\title{
Prototype of Slotted Microstrip Patch Antenna for Multiband Application
}

\author{
Ragini Sharma $^{1 *}$, Mahesh Kumar Aghwariya ${ }^{2}$, Tanvi Agrawal $^{3}$, Sachin tyagi $^{4}$ \\ ${ }^{1,3,4}$ KIET group of Institutions Ghaziabad, India \\ ${ }^{2}$ THDC-Institute of Hydropower Engineering and Technology New Tehri, Uttarakhand, India \\ *Corresponding Author E-mail: ${ }^{1}$ ragini.mits@gmail.com
}

\begin{abstract}
In this paper a slotted microstrip patch antenna has been designed that works for two frequencies $1.42 \mathrm{GHz}$ and $2.65 \mathrm{GHz}$. Since a microstrip patch antenna works only on one resonant frequency so converting that into a multiband patch antenna would enhance the bandwidth and also utilizes the multiple frequencies of operation. This multiband slotted patch antenna is fabricated on FR4 lossy dielectric substrate whose dielectric constant is 4.3 and height is $1.6 \mathrm{~mm}$. The length and width of patch are taken as $51.16 \mathrm{~mm}$ and $39.86 \mathrm{~mm}$ respectively. we cut out the slots so that the patch antenna works at multiple frequencies. Another advantage of presented design is it reduced the size of antenna actually required for $1.42 \mathrm{GHz}$ frequency. Simulation and analysis of slotted patch antenna is done by CST software. Simulation and fabrication results show that the presented antenna design characteristics meet with the standard characteristics of antenna.
\end{abstract}

Keywords-CSTMW studio software, rectangular slot, inset feed, FR4 lossy material, directivity

\section{Introduction}

In the field of wireless communication systems, the operation and designing of antennas plays a pivotal role. In RF communication for transmission and reception of RF signal we need antenna. Now a days we are working on several frequency band for different applications [1]. So constructing an antenna which is much conformal to different surfaces and can work in different bands simultaneously is the need for the advancement of this field[2].

Simulation and fabrication of different structures of microstrip patch antenna and has made progress in recent years. Different characteristics of microstrip patch antenna can be improvedBy changing the structure and dimension of it[3]. Microstrip patch antennas has numerous application field due to certain advantages. It consist light weight, less volume, economic and compatible with integrated circuits so that it can easily install on the rigid surface[4]. Furthermore, they can be easily designed to operate in dual-band, multi-band application, dual or circular polarization.

However, Due to low gain of Patch antennas it is mostly used in ISM band applications. These applications need low power and low profile so we can use patch antenna in indoor and health application[5].

Another problem associated with patch antenna is narrow bandwidth. For incresing the bandwidth many approaches have been utilized such as super substrate, dimensions of antenna, metamaterial, feed network etc [6]. This paper presents a slotted microstrip patch antenna working for two frequencies $1.42 \mathrm{GHz}$ and $2.65 \mathrm{GHz}$ respectively. This prototype is designed obtain a light weight, compact size, and economical antenna with desirable antenna characteristics. One of the important characteristics of antenna is impedance matching. Mismatching of impedance leads to losses and affects the radiation and directivity of antenna [7].
Generally we analyze impedance matching with the help of Smith Chart. CST MW studio software is used for simulation of proposed antenna. (CST MWS) is the leading edge tool for the fast and accurate 3D simulation of high frequency devices and market leader in Time Domain simulation. It enables the fast and accurate analysis of antennas, filters, couplers, planar and multi-layer structures and SI and EMC effects etc [8].

\section{Description of Antenna}

A rectangular patch antenna with two rectangular slot is simulated by using CST MW studio software. This antenna is simulated for FR-4 lossy material with dielectric constant 4.4, loss tangent 0.02 and height $1.6 \mathrm{~mm}$. After designing a rectangular patch antenna two rectangular slots of $14 \times 2 \mathrm{~mm}$ dimensions has been cut at patch antenna. Required Parametric Analysis has given below:

Calculation of Width (W)

$$
W=\frac{1}{2 f_{F} \sqrt{\mu_{0} \varepsilon_{0}}} \sqrt{\frac{2}{\varepsilon_{T}+1}}=\frac{c}{2 f} \sqrt{\frac{2}{\varepsilon_{r}+1}}
$$

Effective dielectric constant is calculated from:

$$
\varepsilon_{\text {eff }}=\frac{\varepsilon_{r}+1}{2}+\frac{\varepsilon_{r}-1}{2}\left(\frac{1}{\sqrt{1+\frac{12 h}{w}}}\right)
$$

The actual length of the Patch (L)

$$
\mathrm{L}=\mathrm{L}_{\mathrm{eff}}-2 \Delta \mathrm{L}
$$


where

Leff $=\frac{c}{2 f f \sqrt{\varepsilon_{x f f}}}$

Calculation of Length Extension

$\frac{\Delta L}{h}=0.412 \frac{\left(\varepsilon_{x f f}+0.9\right)\left(\frac{w}{h}+0.264\right)}{\left(\varepsilon_{\alpha f f}-0.258\right)\left(\frac{w}{h}+0.8\right)}$

where,

$\varepsilon_{\text {reff }}=$ Effective dielectric constant,

$\varepsilon_{r}=$ Dielectric constant of substrate,

$\mathrm{h}=$ Height of dielectric substrate,

$\mathrm{W}=$ Width of the Patch,

$\mathrm{L}=$ Length of the Patch,

$\Delta \mathrm{L}=$ Effective Length,

$\mathrm{f}_{\mathrm{r}}=$ Resonating Frequency

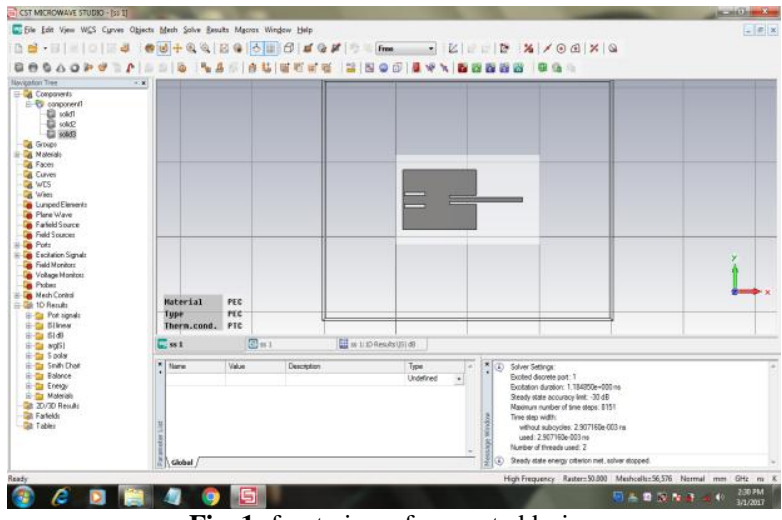

Fig. 1: front view of presenteddesign

The figure 1 shows above represents the structure of slotted Rectangular microstrip Patch whose important specification for designing is mentioned below.

Specification:

1. Dimension of ground plane $=100 \times 60 \mathrm{~mm}$

2. Length of patch $=51.16 \mathrm{~mm}$

3. Width of patch $=39.86 \mathrm{~mm}$

4. Height of patch $=1.6 \mathrm{~mm}$

5. Length of microstrip feed $=51.16 \mathrm{~mm}$

6. Width of microstrip feed $=3 \mathrm{~mm}$

7. Dimensions of slots $=14 \times 2 \mathrm{~mm}$

8. Resonant frequencies $=1.42 \mathrm{GHz}, 1.65 \mathrm{GHz}$

9. Dielectric constant $\varepsilon_{\mathrm{r}}=4.4$

10. Loss tangent $=0.02$

\section{Results and Discussion}

The antenna is analyzed and designed by CST-MWS software at the frequency of $2.65 \mathrm{GHz}$. To convert Micro strip Patch Antenna into Multiband Micro strip Patch Antenna we cuts two equal size rectangular shape slots on patch area of antenna with the dimensions $2 \mathrm{mmx} 14 \mathrm{~mm}$. Initially our antenna was working only on frequency $2.65 \mathrm{GHz}$ but after slot cutting it is working on two resonant frequencies which are $2.65 \mathrm{GHz}$ and $1.42 \mathrm{GHz}$.

The return loss of antenna is shown in Figure 2. The return loss at frequency $2.65 \mathrm{GHz}$ is $-43 \mathrm{~dB}$ and at frequency $1.42 \mathrm{GHz}$ is $-22 \mathrm{~dB}$ which is below $-10 \mathrm{~dB}$ that shows that there is good matching at frequency points [9]. At frequency $1.42 \mathrm{GHz}$,bandwidth is 0.0256 $\mathrm{GHz}$ and at frequency $2.65 \mathrm{GHz}$ bandwidthis $0.0383 \mathrm{GHz}$.

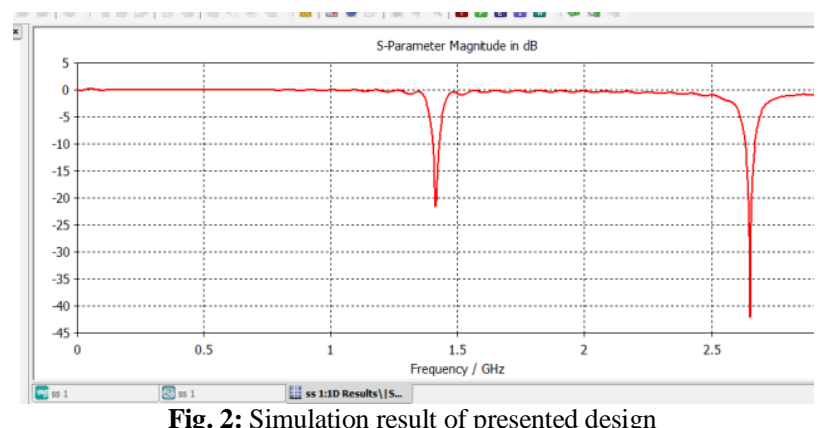

Fig. 2: Simulation result of presented design

Figure 3 shows the smith chart [5] of the microstrip patch antenna. By analysis of Smith chart of presented design it is concluded that impedance of presented design is matched with feed at $1.41 \mathrm{GHz}$ as well as $2.65 \mathrm{GHz}$. At $1.41 \mathrm{GHz}$,impedance of antenna is matched with $52.89 \mathrm{ohm}$ which is near to $50 \Omega$ although due to little mismatching some error occurred [10]. At $2.65 \mathrm{GHz}$, antenna is perfectly matched with $50 \Omega$.

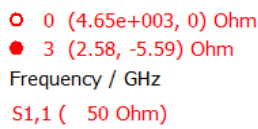

@ $1.412341(52.890356,8.485219) \mathrm{Ohm}$

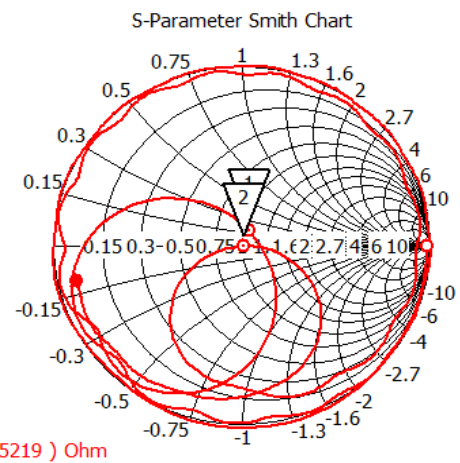

@ $2.651985(50.689534,-0.353486) \mathrm{Ohm}$

Fig. 3: Analysis of impedance matching of presented design

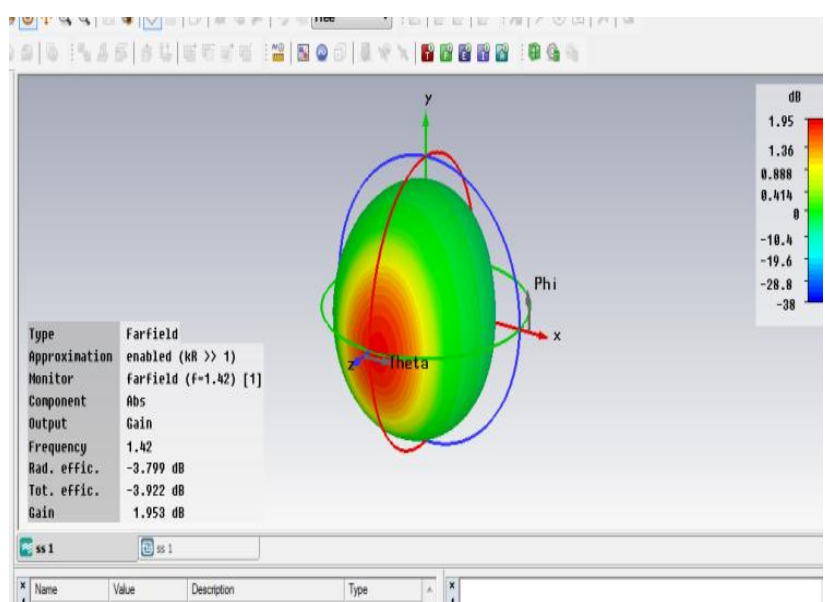

Fig. 4: Gain of presented design at $1.42 \mathrm{GHz}$

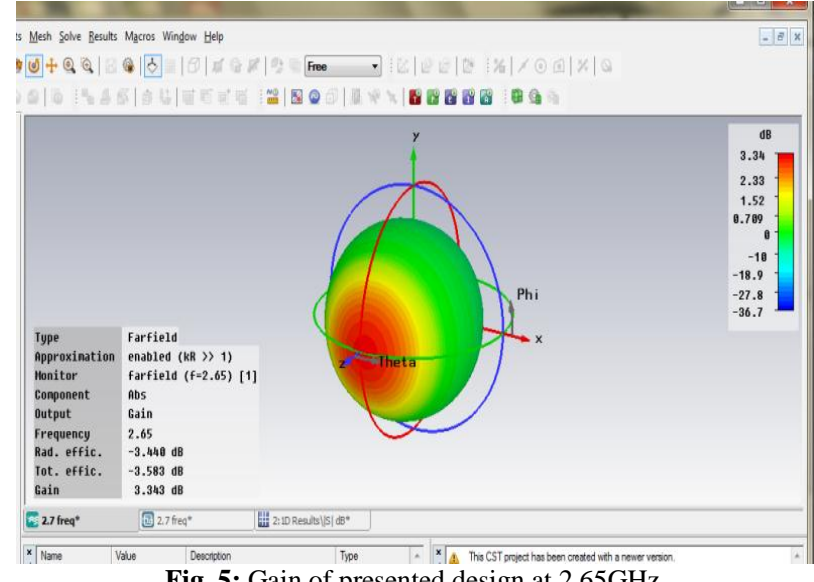

Fig. 5: Gain of presented design at $2.65 \mathrm{GHz}$ 
Figure 4 shows the gain of proposed slotted antenna at frequency $1.42 \mathrm{GHz}$ which is $1.953 \mathrm{~dB}$. Figure 5 shows the gain of proposed slotted antenna at frequency $2.65 \mathrm{GHz}$ which is $3.343 \mathrm{~dB}$ [11].

Figure 6 shows the directivity of proposed design at frequency $1.42 \mathrm{GHz}$. At $1.42 \mathrm{GHz}$ directivity and bandwidth are $5.052 \mathrm{~dB}$ and $0.0256 \mathrm{GHz}$ respectively. At frequency $2.65 \mathrm{GHz}$, directivity and bandwidth are $5.753 \mathrm{~dB}$ and $0.0383 \mathrm{GHz}$ respectively[12].

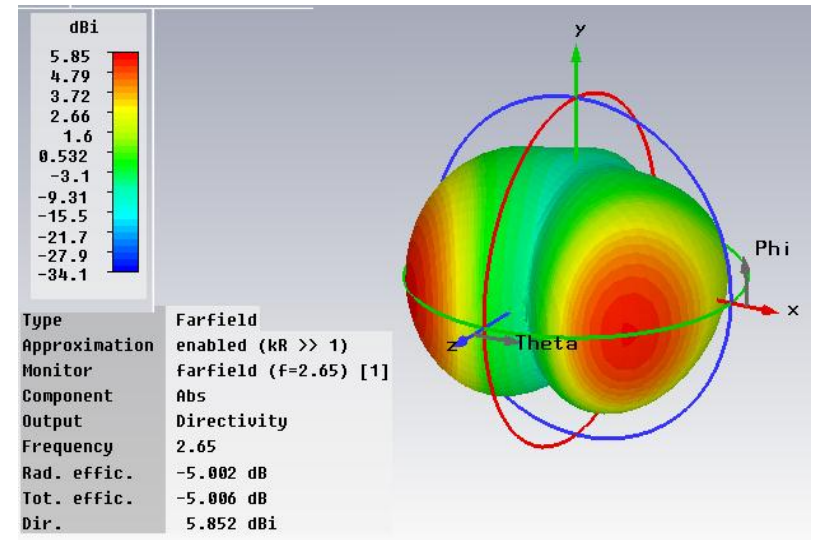

Fig. 6: Directivity at $2.65 \mathrm{GHz}$

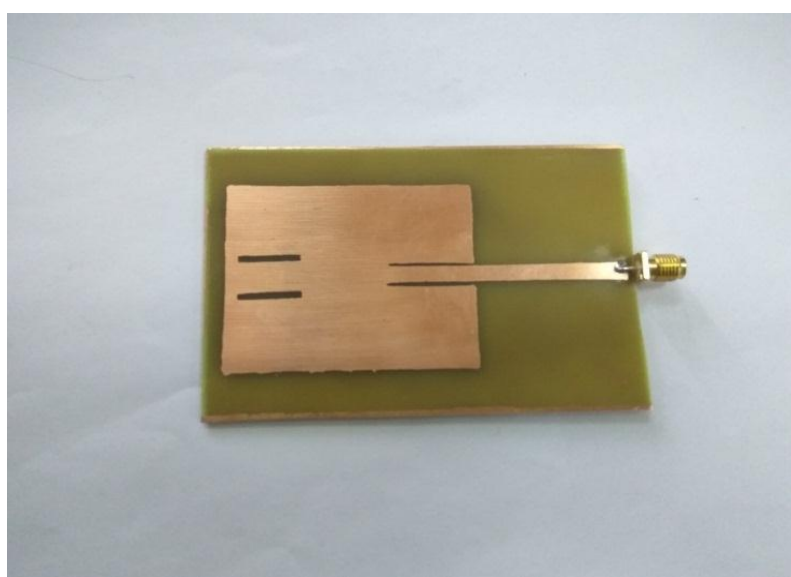

Fig. 7: Antenna Hardware

Hardware of proposed antenna is shown in Figure 7 . The return loss of fabricated antenna at frequency $1.42 \mathrm{GHz}$ is $-18.6 \mathrm{~dB}$ and at frequency $2.65 \mathrm{GHz}$ is $-26.9 \mathrm{~dB}$.

Comparison between Fabricated Antenna Results and Software Simulation Results

\begin{tabular}{|l|l|l|}
\hline Frequencies & $\begin{array}{l}\text { Fabricated Antenna } \\
\text { (Return Loss) }\end{array}$ & $\begin{array}{l}\text { Software Design } \\
\text { (Return Loss) }\end{array}$ \\
\hline $2.65 \mathrm{GHz}$ & $-26.9 \mathrm{Db}$ & $-43 \mathrm{~dB}$ \\
\hline $1.45 \mathrm{GHz}$ & $-18.6 \mathrm{~dB}$ & $-22 \mathrm{~dB}$ \\
\hline
\end{tabular}

\section{Conclusion}

Proposed prototype of slotted rectangular microstrip patch antenna has been simulated and fabricated for two frequencies $1.42 \mathrm{GHz}$ and $2.65 \mathrm{GHz}$ respectively. The return loss at frequency $2.65 \mathrm{GHz}$ is $-43 \mathrm{~dB}$ and at frequency $1.42 \mathrm{GHz}$ is $-22 \mathrm{~dB}$ which is below -10 $\mathrm{dB}$ hence impedance of antenna is matched and return loss is very low . At frequency $1.42 \mathrm{GHz}$, directivity and bandwidth are 5.052 $\mathrm{dB}$ and $0.0256 \mathrm{GHz}$ respectively and at frequency $2.65 \mathrm{GHz}$, directivity and bandwidth are $5.753 \mathrm{~dB}$ and $0.0383 \mathrm{GHz}$ respectively. Gain is $1.953 \mathrm{~dB}$ at frequency $1.42 \mathrm{GHz}$ and 3.343 $\mathrm{dB}$ at frequency $2.65 \mathrm{GHz}$. Fabrication result of presented design are also satisfying required characteristics of antenna.

\section{References}

[1] M. Ben Ahmed, M.Bouhorma, F. Elouaai, A. Mamouni, "Design of new multi standard patch antenna GSM/PCS/UMTS/HIPERLAN for mobile cellular phones", European journal of scientific research ISSN 1450-216X vol.32 No.2(2009), pp 151-157.

[2] Pandey, G. P., Kanaujia, B. K. Gautam, A. K., \& Gupta, S. K.' Ultra-wideband L-strip proximity coupled slot loaded circula microstrip antenna for modern communication systems", Wireless personal communications, 70(1), 139-151.2013.

[3] A Circularly Polarized Octagon-Star-Shaped Microstrip Patch Antenna With Conical Radiation Pattern,IEEE Antennas Wireless Propag. Lett Volume: 66, Issue: 4, April 2018.

[4] NavidRezazadeh ,LotfollahShafai , A Compact Microstrip Patch Antenna for Civilian GPS Interference Mitigation IEEE antennas and wireless propagation letters, vol. 17, no. 3, march 2018

[5] W.L. Stutzman, G.A. Thiele, "Antenna Theory and design", John Wiley \& Sons, 2nd Ed., New York, 1998.

[6] J. S. Colburn and Y. Rahmat-Samii, "Patch antennas on externally perforated high dielectric constant substrates," IEEE Trans. Antennas Propag., vol. 47, no. 12, pp. 1785-1794, Dec. 1999.

[7] Mahesh Kumar Aghwariya, Praful Ranjan, Purnendu Shekher Pandey, Ginni Rani, Ragini Sharma. "Miniaturization of L-Band Rectangular Patch Antenna by Using Two Rectangular Slit" , 2016 8th International Conference on Computational Intelligence and Communication Networks (CICN), 2016.

[8] A. D. Yaghjian and S. R. Best, "Impedance, Bandwidth, and Q of Antennas," IEEE Trans. onAntennas and Propagati'on, Vol. 53, No. 4, pp. $12981324,2005$.

[9] http://www.cst.com/content/products/mws/overview.aspx @ 2012 CST Computer Simulation Technology AG

[10] T. H. O’Donnell and A. D. Yaghjian, Electrically small superdirective arrays using parasitic elements, in Proc. IEEE APS Int. Symp. Albuquerque, NM, pp. 3111-3114, Jul. 2006

[11] David M. Pozar, "Microwave Engineering", $3{ }^{\text {rd }}$ Edition, John Wiley \& Sons, 2015.

[12] Constantine A.Balanis, "Antenna Theory and Design", John Wiley \& Sons, Inc., 2014 